\title{
Control of long-interval performance on mixed cyclic-interval schedules*
}

\author{
JOHN E. KELLO and J. E. R. STADDON \\ Duke University, Durham, North Carolina 27706
}

\begin{abstract}
Pigeons were exposed to a series of cyclic-interval food reinforcement schedules in which each cycle comprised 121 -min intervals followed by 22 -min intervals, 26 -min intervals, or 6 6-min intervals. Response rate was higher and postfood pause shorter in the long (2-or 6-min) than in the short (1-min) intervals. Response rate decreased and pause generally increased across successive 2-min intervals, but response rate increased and pause generally decreased across successive 6-min intervals. Performance in the 2-min intervals is consistent with a temporal discrimination account, but performance in the 6-min intervals supports earlier suggestions that some other factor (response "momentum") may be involved when the long intervals are sufficiently longer than the short.
\end{abstract}

On simple fixed-interval (FI) schedules of reinforcement, pigeons respond at lower rate in longer intervals, where reinforcement is less frequent (Schneider, 1969). If, however, interreinforcement duration varies within a session in a repeating cyclic pattern consisting of a series of relatively short fixed intervals followed by a series of longer fixed intervals, without discriminative stimuli to differentiate the two components (a mixed cyclic-interval schedule; Innis \& Staddon, 1970), the opposite relation is obtained; response rate is higher in the long-interval part of the cycle (Staddon, 1964, 1967, 1969), in violation of the usual "matching" relationship between reinforcement frequency and response rate (cf. Herrnstein, 1970).

With a mixed cyclic-interval schedule in which each cycle consisted of 12 consecutive 1-min intervals followed by 4 3-min intervals (12 FI 1, 4 FI 3), Staddon (1967) showed that the paradoxical higher response rate in the long than in the short intervals resulted from a constant postreinforcement pause appropriate in length to the 1-min intervals, followed by responding at a steady rate regardless of the actual length of the interval. The Ss appeared to be "set" to the shortest interreinforcement time they experienced $(1 \mathrm{~min})$. Their performance may be described as a failure to discriminate long from short intervals within a session.

On a 12 FI 1, 6 FI 2 mixed cyclic-interval schedule, it has been shown that pause increases and response rate decreases across the six long intervals, both performance measures approaching typical values for simple FI $2 \mathrm{~min}$ (Innis \& Staddon, 1970). While there is no complete

\footnotetext{
*The research reported here is based on a Master's thesis submitted to Duke University by the first author under the direction of the second author. It was supported by a grant from the National Science Foundation to Duke University, J. E. R. Staddon, principal investigator, and by a Biomedical Sciences Support Grant from Duke University to J. E. Kello. We thank Nancy $K$. Innis for assistance with the experiments and Janice Frank and Bettie C. Starr for critical comments on the manuscript. Reprints may be obtained from John E. Kello, Department of Psychology, Duke University, Durham, North Carolina 27706.
}

"failure to discriminate" here, as on the 12 FI 1, 4 FI 3 schedule, the 12 FI 1,6 FI 2 result also falls readily within the scope of a simple interval-discrimination account. Presumably, the longer the long intervals and the more of them in a series, the more discriminable they will be from the short intervals, to the point where responding on the long intervals becomes appropriate to simple fixed intervals of that length (Innis \& Staddon, 1970). Thus, on 12 FI 1, 6 FI 2, the decrease in long-interval duration compared to 12 FI 1, 4 FI 3 is more than offset by the increase in the number of long intervals in a series, so that the Ss begin to discriminate the long intervals from the short as early as the second long interval, as they do not on 12 FI 1, 4 FI 3.

However, the results with a similar 12 FI 1, 2 FI 6 schedule are not explicable in terms of temporal discrimination. On this schedule, pause decreases and response rate increases across long intervals, becoming even less appropriate to simple FI 6-min performance than behavior on the first long interval (Innis \& Staddon, 1970). Innis and Staddon labeled this effect response "momentum," and suggested that it might represent a nondiscrimination behavioral process which could override discrimination when long intervals were sufficiently long.

The present experiment sought to replicate Innis and Staddon's (1970) results with the 12 FI 1, 2 FI 6 schedule and to compare these results with performance on 12 FI 1, 2 FI 2, and 12 FI 1, 6 FI 6 schedules. The 12 FI 1, 2 FI 2 schedule should, according to Innis and Staddon, minimize the discriminability of the long from the short intervals since long-interval length differs relatively little from short-interval length and the number of long intervals in a series is only two. Hence, long-interval performance would be expected to parallel that found on 12 FI 1, 4 FI 3 (Staddon, 1967), with no systematic change in pause and response rate across the long intervals, indicating a failure to discriminate the long intervals from the short. The pattern of performance across long 


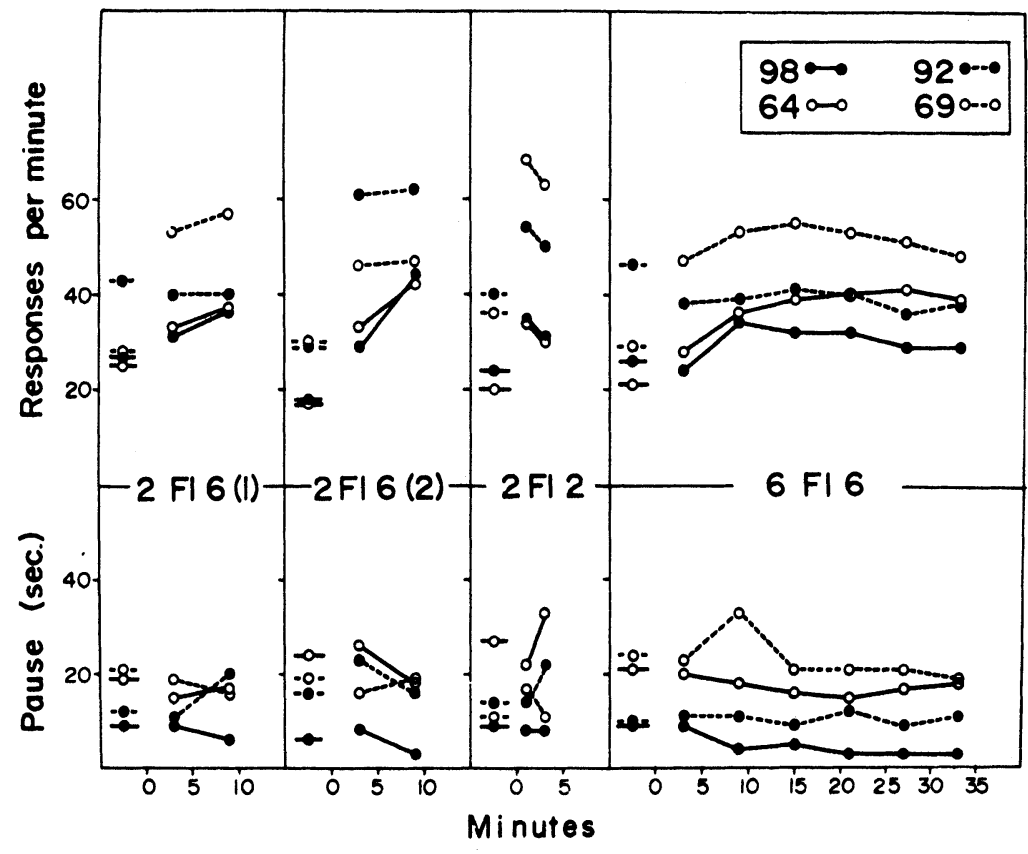

Fig. 1. Mean response rate (upper half) and pause duration (lower half) for each bird on the four experimental conditions. The connected points in each panel show performance across the run of long intervals, while the single points to the left summarize performance on the short intervals. All data are averaged across the last 5 days on each condition. intervals on the $12 \mathrm{FI} \mathrm{1,} 6$ FI 6 schedule is not easy to predict since, in Innis and Staddon's terms, this schedule should enhance long-interval discriminability, but may also involve response momentum. Comparison of performance on these schedules should shed further light on factors determining the inverse relationship between reinforcement frequency and response rate obtained on mixed cyclic-interval schedules.

\section{METHOD}

\section{Subjects}

The Ss were four adult male White Carneaux pigeons with previous experience on progressive-interval schedules (Innis \& Staddon, 1971), on which interreinforcement duration increased and decreased very gradually (Birds 98, 69, and 92), and on variable-interval schedules (Bird 64). They were maintained at $80 \%$ of their free-feeding weights throughout.

\section{Apparatus}

A custom-built Skinner box with internal dimensions of approximately $30 \times 25 \times 20 \mathrm{~cm}$ was used. Pecks on the Plexiglas response key were followed intermittently by a 3-sec presentation of a food magazine containing mixed grain. During this reinforcement event, the magazine light was turned on and the houselight and keylight, normally on, were extinguished. Each effective keypeck (minimum force $.18 \mathrm{~N}$ ) produced an audible feedback "click." All programming and recording equipment was located in an adjacent room. White noise and the noise from a ventilating fan masked extraneous sounds.

\section{Procedure}

The Ss were exposed to a series of two-valued mixed cyclic-interval schedules. Since the "short" part of a cycle always consisted of 121 -min intervals, experimental conditions are here identified only by the run length (number of intervals) and duration of the intervals making up the "long" part of the cycle. Sessions always began with the first 1-min interval of a series and terminated after three complete short-long cycles. The keylight was white throughout the session. There were four phases of training: (1) Initially, all Ss were trained for 30 sessions on a 2
FI 6 schedule identical to that used by Innis and Staddon (1970). (2) Two of the birds (98 and 64) were then switched to a 2 FI 2 schedule, while the remaining birds $(92$ and 69$)$ were switched to 6 FI 6 (16-17 sessions). (3) Next, Birds 98 and 64 were switched to 6 FI 6, and Birds 92 and 69 were switched to 2 FI 2, for 16-17 sessions. (4) Finally, all Ss were returned to the original 2 FI 6 schedule for 14-16 sessions. The grouping of Ss for the second and third phases of training was based on their long-interval performance on the first phase, the initial exposure to 2 FI 6. Birds 98 and 69 both clearly showed the 2 FI 6 pattern of pausing and responding reported by Innis and Staddon (1970), whereas Birds 92 and 64, in terms of one or both performance measures, did not. Therefore, to keep the groups as similar as possible, Birds 98 and 69 were separated and their respective partners were chosen by chance. Conditions were switched only af ter performance for all Ss was judged stable for at lecsst 5 days by examination of cumulative records and digital printout data. Ss were run daily throughout the experiment.

\section{RESULTS}

Figure 1 summarizes mean response rate (upper half) and pause duration (lower half) data for each of the four Ss on each of the experimental conditions. The connected points in the right portion of each panel show performance on the consecutive long intervals of the average cycle, while the unconnected single points to the left represent mean performance on the short-interval part of the average cycle. Since behavior in the first few intervals of a session often differed from stable performance throughout the rest of the session, the short-interval segment of the first cycle was omitted in determining mean short-interval performance.

The first panel of Fig. 1 shows that on the initial exposure to 2 FI 6 [i.e., 2 FI 6 (1)], all Ss except Bird 92 exhibited a higher overall rate of responding in the long intervals than in the short intervals, and showed a moderate increase in response rate across the two long 
Fig. 2. Cumulative records showing characteristic steady-state long-interval performance for each $S$ on 2 FI 6 (1) in Part A, and 6 FI 6 (first three long intervals) in Part C; Part B shows for each $S$ the short-interval segment just preceding the long-interval segment shown in Part C. Downward deflections of the pen denote reinforcements, and therefore mark off successive intervals. Each record shown was selected from the last session on a given condition.

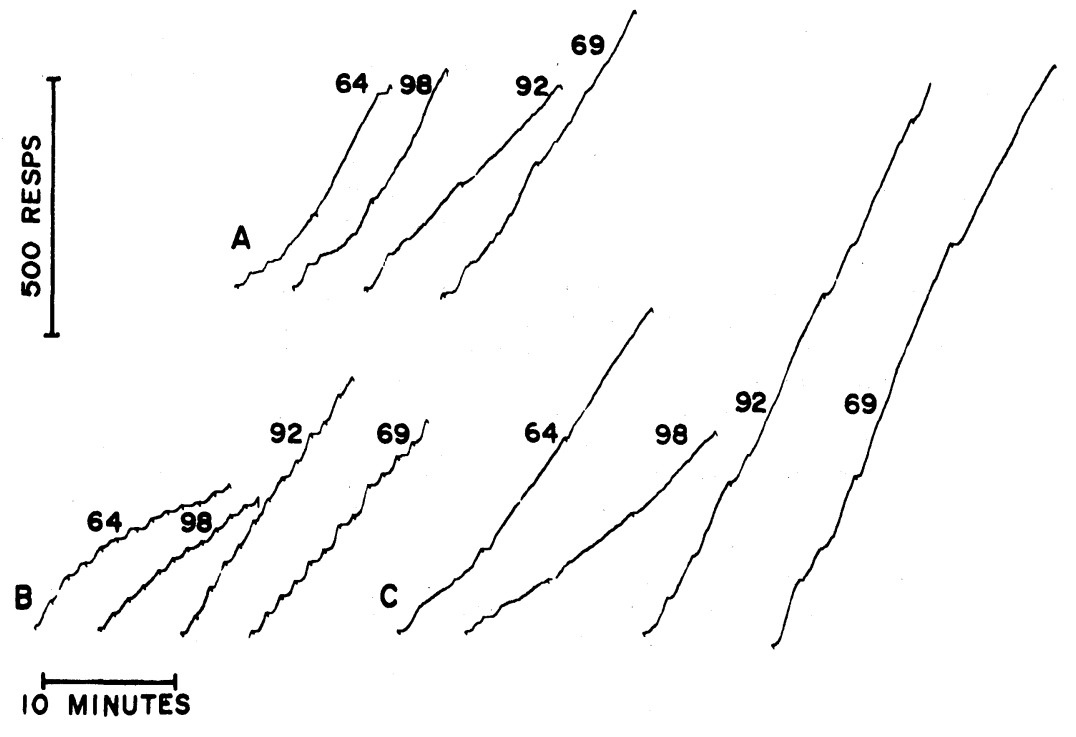

intervals. Pause decreased across the long intervals for Birds 98 and 69, but increased for Birds 92 and 64. On the second exposure to this schedule, 2 FI 6 (2), which was separated from 2 FI 6 (1) by training on 2 FI 2 and 6 FI 6, all of the Ss showed both a higher overall response rate in the long than in the short intervals and an increase in response rate across the two long intervals (Fig. 1, second panel). Pause decreased across the long intervals on 2 FI 6 (2) for all except Bird 69.

On 2 FI 2, as shown in the third panel of Fig. 1, rate of responding was greater in the long intervals than in the short, and decreased across the two long intervals. Pause data were again much less consistent, with pause increasing across long intervals for Birds 92 and 64, decreasing for Bird 69, and showing no change for Bird 98.

On 6 FI 6 (Fig. 1, last panel) overall response rate in the long intervals was greater than in the short except for Bird 92. For Birds 98, 69, and 64, response rate increased across the first two or three long intervals and remained at a high level for the duration of the long-interval segment of the cycle. Pause tended to decrease slightly across long intervals (Birds 98, 64, 69) or to remain constant (Bird 92).

Cumulative records of asymptotic performance revealed that moment-to-moment responding in the first long interval of a series was often erratic, with pauses and abrupt variations in rate after 1-2 min, while the response rate in subsequent long intervals was high and more nearly constant throughout the interval. This is shown in representative cumulative records for each $\mathrm{S}$ on 2 FI 6 (1) in Part A of Fig. 2, and for each S in the first three intervals on 6 FI 6 in Part C. (Note that Part B shows the short-interval segments preceding the long-interval segments plotted in C.) This effect, common when long intervals were $6 \mathrm{~min}$, was almost never seen when they were $2 \mathrm{~min}$ (see also Innis \& Staddon, 1970).

\section{DISCUSSION}

The present results show, with each cyclic-interval schedule, the paradoxical inverse relation between rate of responding and frequency of reinforcement found with other mixed cyclic-interval schedules (Staddon, 1964, 1967, 1969; Innis \& Staddon, 1970). The results also replicate Innis and Staddon's earlier findings with a 12 FI 1, 2 FI 6 schedule, and show that discrimination alone is not sufficient to account for performance on these schedules. In terms of interval discrimination, response rate across six 6-min intervals should not increase (nor on 2 FI 6), but should decrease to a level below that on the 1-min intervals, indicating discrimination of long from short, while response rate across two 2 -min intervals should not change, indicating no discrimination. Neither result was obtained.

On all the two-valued mixed cyclic-interval schedules studied thus far, Ss do not anticipate the abrupt shifts in interreinforcement duration. Thus, their pause in the first long interval of a series is appropriate in length to the preceding short intervals. Response rate in this first long interval may be erratic, especially if the intervals are relatively long, but is much higher than is appropriate to the fixed-interval duration (cf. Schneider, 1969). It remains to be explained why response rate is high throughout the first long interval, when reinforcement comes only after 1-min or after some much longer period. Given the short pause and high response rate in the first long interval, subsequent long-interval performance within the parameters studied thus far appears to be a simple function of long-interval duration: the longer the interval, the less appropriate the change in response rate across a run of long intervals. Varying run length per se apparently does not influence discriminability as was earlier hypothesized (Innis \& Staddon, 1970). Thus, given a short-interval segment of 12 FI 1 , when the long intervals are $2 \mathrm{~min}$, response rate decreases appropriately from its initial high value on the first long interval, and pause increases, across two or six (cf. Innis \& Staddon, 1970) 2-min intervals. This result with 2-min long intervals suggests, in Innis and Staddon's terms, the operation of discrimination and only minimal effects of response momentum. When the long intervals are 3 min (Staddon, 1967), pause and responding remain at approximately the same initial levels across four long intervals, suggesting that compared to 2-min long intervals, the stronger momentum cancels the presumed increase in discriminability. When the long intervals are $6 \mathrm{~min}$, response rate increases and pause generally decreases (though pause data in the present experiment were rather erratic) across two or six long intervals. Unpublished 
experiments in our laboratory have shown that this response elevation may persist across as many as 126 -min long intervals at asymptote. With $6 \mathrm{~min}$ intervals, then, "momentum" overrides discrimination.

Thus, the data presently available can be encompassed by a discrimination-momentum account as suggested by Innis and Staddon (1970). "Momentum" is, of course, still a rather ad hoc notion in this context, not readily related to other operant literature. But, the response increase in 6-min long intervals, which led to the postulation of "momentum," is not easily accountable in terms of more familiar constructs dealing with response elevations, such as frustration or behavioral contrast. For example, behavioral contrast as usually understood requires differential stimuli associated with different schedule components (cf. Staddon, 1974), which is not the case with these mixed cyclic-interval schedules. And, at any rate, a contrast effect in the long intervals as a function of the preceding short intervals would be in the direction of decreasing rather than increasing responding (cf. Kello, Innis, \& Staddon, 1974). There are problems with a frustration account as well. Chief among these is that delay of reinforcement (corresponding to the increase in time to reinforcement in the long intervals) appears in other experimental situations not to be a frustrative event; there is no appreciable increase in responding after reinforcement when it is finally presented (e.g., Sgro, 1969). Additionally, the applicability of frustration even to the effects of reinforcement omission on fixed-interval schedules has recently been seriously challenged (Kello, 1972; Staddon, 1970; Staddon \& Innis, 1969).

One kind of simpler account of performance on 6-min long intervals can be ruled out, though others may still be possible. One might speculate that the increase in responding across long intervals on 12 FI 1,2 FI 6 reflects, not response momentum, but simply the Ss' anticipating the impending increase in reinforcement frequency (1-min intervals). This account would of course encounter problems with the fact that the elevation increases or at least persists across 6 , or even 12, 6-min long intervals. At any rate, if it were true, even for the 12 FI 1, 2 FI 6 case, then providing an exteroceptive stimulus to signal the first $1-\mathrm{m}$ in interval in a series should reduce or eliminate this response elevation. But, further unpublished experiments in our laboratory have shown that the presence of a green keylight instead of the usual white in the first short interval in a series has no effect, transient or steady-state, on the long-interval response elevation on 12 FI 1, 2 FI 6.

\section{REFERENCES}

Herrnstein, R. J. On the law of effect. Journal of the Experimental Analysis of Behavior, 1970, 13, 243-266.

Innis, N. K., \& Staddon, J. E. R. Sequential effects in cyclic-interval schedules. Psychonomic Science, 1970, 19, 313-315.

Innis, N. K., \& Staddon, J. E. R. Temporal tracking on cyclic-interval reinforcement schedules. Journal of the Experimental Analy sis of Behavior, 1971, 16, 411-423.

Kello, J. E. The reinforcem ent-omission effect on fixed-interval schedules: Frustration or inhibition? Learning \& Motivation, $1972,3,138-147$.

Kello, J. E., Innis, N. K., \& Staddon, J. E. R. Alternate stimuli on multiple fixed-interval schedules. Submitted for publication, 1974

Schneider, B. A. A two-state analy sis of fixed-interval responding in the pigeon. Journal of the Experimental Analysis of Behavior, 1969, 12, 677-688.

Sgro, J. A. Complete removal and delay of sucrose reward in the double alleyway. Journal of Comparative \& Physiological Psychology, 1969, 69, 442-447.

Staddon, J. E. R. Reinforcement as input: Cyclic variable-int erval schedule. Science, 1964, 145, 410-412.

Staddon, J. E. R. Attention and temporal discrimination: Factors controlling responding under a cyclic-interval schedule. Journal of the Experimental Analysis of Behavior, 1967, 10, 349-359.

Staddon, J. E. R. Multiple fixed-interval schedules: Transient contrast and temporal inhibition. Journal of the Experimental Analy sis of Behavior, 1969, 12, 583-590.

Staddon, J. E. R. Temporal effects of reinforcement: A negative "frustration" effect. Learning \& Motivation, 1970, 1, 227-247.

Staddon, J. E. R. A note on behavioral contrast and frustration. Quarterly Journal of Experimental Psychology, 1974, in press.

Staddon, J. E. R., \& Innis, N. K. Reinforcement omission on fixed interval schedules. Journal of the Experimental Analysis of Behavior, 1969, 12, 689-700.

(Received for publication March 11, 1974.) 